Little Free Libraries

\section{A Call for Research into the Tiny Book Depositories}

MARIANNE SNOW

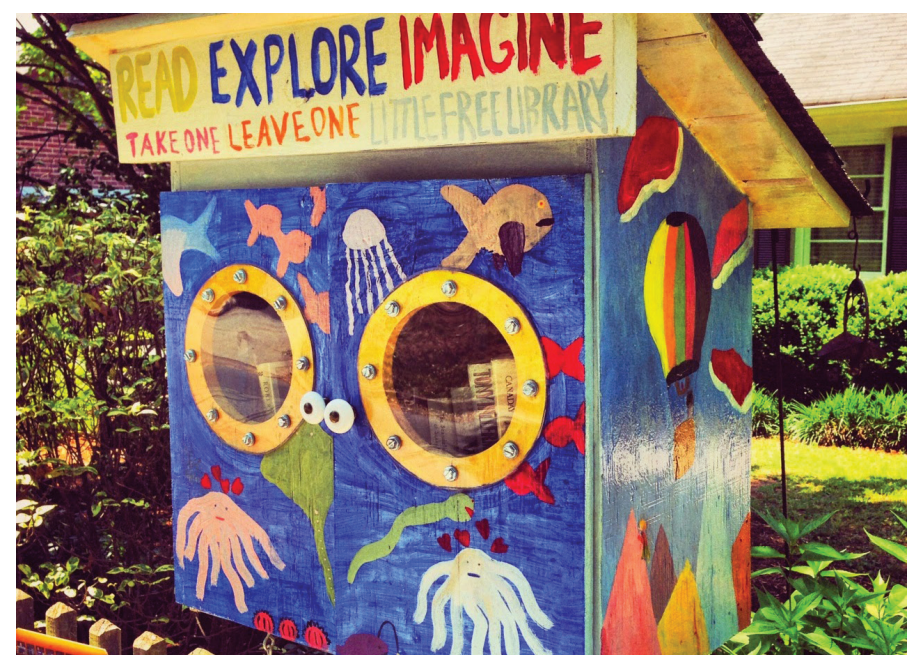

address? Then, since the LFL movement is a new phenomenon and as yet untouched by scholars, I will suggest directions for future research on this topic. Given the widespread presence of LFLs in many countries, I argue that this movement is worthy of attention.

\section{Libraries, Access to Books, and Social Exclusion}

When it comes to obtaining reading materials, many children and families encounter challenges, such as the inability to afford children's books or other literacy materials. ${ }^{4}$ While a seemingly logical solution to this problem is checking out books for free at a local public library, these families might face additional difficulties. One major hindrance is the relative lack of resources at many public and school libraries serving low-income neighborhoods. Although libraries have long branded themselves as great equalizers, in that they make literacy materials and other sources of information available for anyone and everyone, ${ }^{5}$ studies have indicated that this claim is not necessarily true. Ensuring that all libraries, regardless of the populations they serve, have equal resources does not guarantee a "level playing field" for families of varying income levels. ${ }^{6}$ Rather, libraries in low-income areas should provide families and children with more resources-more

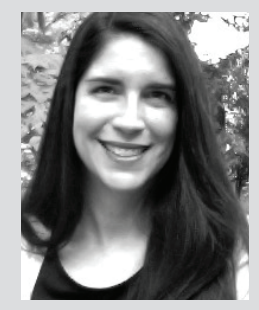

Marianne Snow is a doctoral student at the University of Georgia, where she researches Latin@, Latin American, and nonfiction children's literature; teacher education; and Latin@ children's and families access to books. Before beginning graduate school, she taught pre-kindergarten in Houston, Texas. 


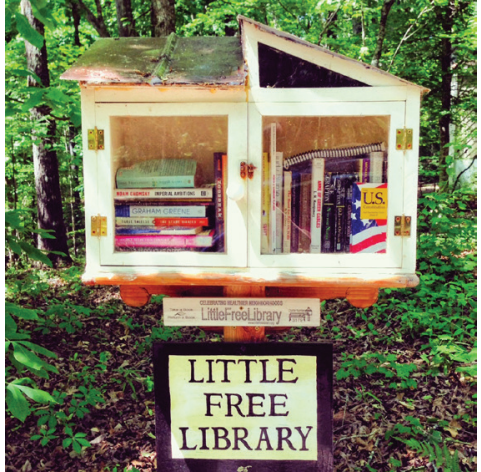

funding, books, computers, better-trained librarians, etc.-than their counterparts in more affluent neighborhoods. ${ }^{7}$

Another obstacle lowincome families often face at libraries is social exclusion, ${ }^{8}$ or difficulty accessing these institutions due to their "lack of cultural and educational capital ... and power." ${ }^{9}$ For example, children and families possessing less cultural and educational capital may feel alienated because they feel that only well-educated people use libraries, they do not know how to use a library, or they "feel stupid" asking questions. ${ }^{10}$ Additionally, many immigrants affected by poverty — another oft-marginalized group ${ }^{11}$ — come from cultures where socializing in public places is the norm and therefore may feel uncomfortable with the enforced silence and language barriers at public libraries in the United States. ${ }^{12}$ Schools serving high-poverty areas, meanwhile, are also not equipped to provide their students with ideal library services, since they may have fewer resources than schools serving more affluent communities. ${ }^{13}$

Simply put, for various reasons, public and school libraries aren't reaching some children and families. Fortunately, many libraries and library advocates are making efforts to address excluded community members' needs more effectively, ${ }^{14}$ and advocates assert that LFLs are an effective strategy for confronting these issues. On their website, the Little Free Library organization states that their mission is "to promote literacy and the love of reading by building free book exchanges worldwide" and "to build a sense of community as we share skills, creativity, and wisdom across generations." ${ }^{15}$ In my city, LFLs sponsored by a community literacy initiative claim the following benefits: ${ }^{16}$

- LFLs are open twenty-four hours per day and require no library card-features that might attract people who feel unwelcome or uncomfortable in public or school libraries.

- The absence of due dates for returning books allows people to keep books longer and actually finish them.

- LFLs can be erected almost anywhere, meaning that communities that are underserved or not served by established libraries can have easier access to larger amounts of reading materials.

Furthermore, Bol recently started a Kickstarter campaign to raise money to install LFLs in "book deserts"- areas where people lack access to libraries and may not be able to afford books. ${ }^{17}$

According to these sources, Little Free Libraries can provide a solution to the problems of inadequate resources and social exclusion in libraries - they are created and managed by people they serve, they are free and open, and they are not attached to any formal institution that might be off-putting to children and families in marginalized communities. Given LFLs' popularity and their wonderful alleged benefits, it seems that they would be a welcome relief in socially excluded communities, right?

\section{Further Questions}

Not so fast-we must still answer many questions to determine whether LFLs actually serve their purpose. For instance, two years ago a reporter for the Spokesman-Review in Spokane, Washington, wondered whether anyone other than already avid readers would actually visit and use an LFL, ${ }^{18}$ and thus far, no research exists that investigates questions like his. Right now, the topic of Little Free Libraries is an untouched issue, waiting to be explored. Therefore, I encourage scholars, librarians, teachers, and community members to conduct their own research on these fascinating little book boxes. We can consider questions such as:

- Where are LFLs typically located? Are they more often located in affluent neighborhoods, communities affected by poverty, urban centers, suburbs, rural areas?

- How often do books circulate in LFLs, and who is borrowing and lending books?

- Which age levels do the books in LFLs typically target-children, teenagers, adults?

- Which genres of children's and young adult books are most common in the libraries?

- How diverse are the books found in the libraries? Are the books culturally relevant? In other words, do they reflect the cultures represented where they are located?

Pursuing these questions using a variety of research methods and theoretical stances will ideally yield rich data on the effectiveness of LFLs. Also, community members can perform more casual research in their own neighborhoods by observing how local LFLs are being used, conducting interviews with LFL stewards and patrons to learn more about their experiences utilizing the libraries; regularly recording the numbers, genres, and cultural diversity of the books people deposit and borrow; and studying the locations of libraries to determine their proximity to culturally and socioeconomically diverse communities.

During the past few months, I've utilized these methods to start investigating the LFLs in my city more closely, and while several stewards-including some school and public librarians-I've interviewed maintain they're "amazing," "an excellent idea," and "encourag[e] kids to read," my observations of local LFLs don't always back up these claims. For example, most of the LFLs in my area are in very affluent areas; contain children's books that mostly depict white, affluent characters; and don't seem to be used very often. Are these LFLs really reaching 


\section{The Lutie Stearns Connection}

Founder of the Wisconsin Free Library Commission, Lutie Stearns helped create fourteen hundred traveling libraries in Wisconsin between 1896 and 1914." Each traveling library-a strong trunk housing about thirty books of various genres that would appeal to diverse readers ${ }^{\dagger}$-brought reading materials to isolated communities, work camps, hospitals, and orphanages, and many collections contained books in foreign languages spoken in the state, like Norwegian, Yiddish, German, and Polish. ${ }^{\ddagger}$ This successful booksharing system led to the establishment of many public libraries across Wisconsin. ${ }^{\S}$

* Christine Pawley, "Advocate for Access: Lutie Stearns and the Traveling Libraries of the Wisconsin Free Library Commission, 18951914," Libraries \& Culture 35, no. 3 (2000): 441.

† Stuart Stotts, "A Thousand Little Libraries: Lutie Stearns, The Johnny Appleseed of Books," Wisconsin Magazine of History 90, no. 2 (2006): 42.

‡ Pawley, "Advocate for Access," 441.

$\S$ Stotts, "A Thousand Little Libraries," 46-47.

everyone in my community? And what about LFLs in other communities, both in the United States and around the world?

If we continue to observe and investigate LFLs in various locations and discover that they are, for the most part, achieving their intended purpose of reaching marginalized children and families, then we can continue to promote these resources and encourage their dissemination not only in the United States but also in communities around the world. On the other hand, if we perchance find that LFLs don't really make reading materials more accessible to people who feel socially excluded, then the Little Free Library non-profit organization and supporters can use research data to address any concerns and make LFLs more effective. Overall, if we want Little Free Libraries to be successful, we need to systematically assess their viability on a larger scale—so let's get started.

\section{References}

1. “Our Map,” Little Free Library, accessed May 19, 2015, www.littlefreelibrary.org/ourmap.

2. "The History of Little Free Library," Little Free Library, accessed May 20, 2015, www.littlefreelibrary.org/ ourhistory. All information about the history of the Little Free Library movement comes from this source.
3. "What Is a Little Free Library?," Little Free Library, accessed May 20, 2015, www.littlefreelibrary.org.

4. Gary W. Evans, "The Environment of Childhood Poverty," American Psychologist 59, no. 2 (2004): 77.

5. Abigail Van Slyck, Free to All: Carnegie Libraries \& American Culture, 1890-1920 (Chicago: University of Chicago Press, 1995), 201.

6. Susan B. Neuman and Donna Celano, "The Knowledge Gap: Implications of Leveling the Playing Field for LowIncome and Middle-Income Children," Reading Research Quarterly 41, no. 2 (2006): 197; Anne McGill-Franzen et al., "Putting Books in the Classroom Seems Necessary But Not Sufficient,” Journal of Educational Psychology 94 (1999): 67.

7. Kevin Carey, The Funding Gap (Washington, DC: Education Trust, 2003), 12.

8. Ajit Bhalla and Frédéric Lapeyre, "Social Exclusion: Towards an Analytical and Operational Framework," Development and Change 28 (1997): 415.

9. David Muddiman et al., Open to All? The Public Library and Social Exclusion (Birmingham, UK: The Council for Museums, Archives, and Libraries, 2000), 2.

10. Annette DeFaveri, "Breaking Barriers: Libraries and Socially Excluded Communities,” Information for Social Change 21 (2005): 1-2.

11. Christopher J. Lyons, María B. Vélez, and Wayne A. Santoro, "Neighborhood Immigration, Violence, and City-Level Immigrant Political Opportunities," American Sociological Review 78, no. 4 (2013): 604.

12. John Gehner, "Libraries, Low-Income People, and Social Exclusion,” Public Library Quarterly 29 (2010): 43.

13. Shana Pribesh, Karen Gavigan, and Gail Dickinson, "The Access Gap: Poverty and Characteristics of School Library Media Centers," Library Quarterly 81, no. 2 (2011): 155.

14. See John Gehner, "Libraries, Low-Income People, and Social Exclusion," 39-47; John Pateman, "Developing a Needs Based Library Service,” Information for Social Change 26 (2004): 8-28.

15. "The History of Little Free Library."

16. April Burkhart, "Athens Little Library Offers Free Books, Supports Literacy," Athens Banner-Herald, March 24, 2013, http://onlineathens.com/local-news/2013-03-24/athenslittle-library-offers-free-books-supports-literacy.

17. Todd Bol, "Little Free Library Big Book Access," accessed May 21, 2015, https: / /www.kickstarter.com/ projects/490112915/little-free-librarys-big-book-access -project

18. Adrian Rogers, "It Seems That Only Readers Are Checking Out Little Free Libraries," Spokesman-Review, November 18, 2012, www.spokesman.com/stories/2012/nov/18/ abridged-selection. 